\title{
A Reference Process to Design Information Systems for Sustainable Design Based on LCA, PSS, Social and Economic Aspects
}

\author{
Fabiana Soares Santana $^{1}$, Claudio Barberato ${ }^{2}$, and Antonio Mauro Saraiva ${ }^{3}$ \\ ${ }^{1}$ Universidade Federal do ABC, Brazil \\ ${ }^{2}$ Centro Universitário da FEI, Brazil \\ ${ }^{3}$ Universidade de São Paulo, Brazil \\ fabiana.santana@gmail.com, claudio.barberato@gmail.com, \\ saraiva@usp.br
}

\begin{abstract}
The purpose of Sustainable Design, SD, is to satisfy customer needs while reducing environmental impacts. The main challenge is to integrate Life Cycle Assessment, Product Service Systems, social and economic aspects while considering the tensions and trade-offs of each activity in depth. SD requires data from many sources in addition to many software tools to perform each analysis. In order to provide information systems for SD, the adoption of a Service-Oriented Architecture, SOA, is appropriate because of its integration requirements. SOA best practices recommend the design of a reference process prior to architectural definitions, so as to identify the complexities and provide a comprehensive solution to the problem. A reference process is presented here as the first step for building information systems for SD. In addition, the reference process presents a list of activities to be performed during the design stage and is very helpful as a guide for SD beginners.
\end{abstract}

Keywords: SOA, Reference Process, Sustainable Design, Information Systems, Information Systems to Support Sustainable Design.

\section{Introduction}

Sustainable Development is "the development that meets the needs of the present without compromising the ability of future generations to meet their own needs" [3]. Eco-Efficiency addresses the delivery of products and services, raising the quality of life, reducing ecological impacts to acceptable levels and providing competitive prices [10]. Cleaner Production [http://www.uneptie.org/pc/cp/home.htm] is the continuous application of environmental strategies so as to increase Eco-Efficiency [6]. One of the main purposes of Cleaner Production is reducing the environmental impacts that, despite all concerns about the subject, continue to grow [6, 23].

Climate change and ecological disasters attributed to global warming, are leading to the establishment of legal and trade restrictions related to the development of products and services so as to increase their sustainability [26, 29]. This is known as Sustainable Design, SD, or Design for Sustainability. Product Service System [29], 
PSS, is a system proposed to create new products and services focused on meeting the client's needs, eventually replacing products for services or vice versa, or modifying the existing productive processes. Life Cycle Assessment, or LCA, is a standard technique $[20,21]$ used to evaluate the impact of a product on the environment.

SD is a highly complex activity with many tensions and trade-offs, and one of its main challenges is to design products integrating PSS concepts and LCA techniques to the social and economic aspects of the production process. The purpose is to offer a complete and realistic evaluation of the environmental burden caused by a product or a service. This complexity can be reduced with the development of appropriate information systems for SD. Software tools to assist in the design activity and for performing analysis and evaluations of quantitative aspects of SD would be very helpful to the designer.

Information systems for SD will demand resources for integration and interoperability with other systems and data, obtained from many potential different providers, since it requires information about raw material, the productive process, the product disposal and many others. Hence, a solution based on Service-Oriented Computing, SOC, is recommended [2, 31].

The development of a SOC-based solution may start with the design of a ServiceOriented Architecture, SOA. A SOA-based solution may start with the definition of a reference process to present a clear elicitation of the tasks to be performed and to include the experts' knowledge in a single process view [8].

A reference process is thus presented here to address the requirements of an information system for SD. This is the first step for defining a SOC-based software solution for this problem. As additional benefits, the reference process can show improvements in the design activity and can be very useful for beginners, as a guide to SD.

\section{Evaluating the Environmental Burden}

This section presents basic concepts related to the evaluation of the environmental burden of products and services, and strategies to try and reduce it.

\subsection{Processes, Products, Services and the Environment}

A process is a collection of steps, arranged in a sequence and following a particular set of rules. The decomposition of a domain is recommended as a starting point to identify the problems to be solved in a SOA-based system [19]. This can be achieved by designing a process in which the steps required are described with the respective inputs and outputs.

A reference process in SOA maps the detailed information contained in an existing standard or model [1, 32]. It summarizes and organizes the knowledge about a subject. Besides documenting and formalizing current practices, a reference process may be a guide to define each specific step of the process and can also be applied to identify gaps, extra work, failures and improvements. It represents an important tool for a software architect because it condenses all the knowledge about the problem in a single diagram. 
SD must consider the conservation of raw materials, energy and water, the reduction of emissions and wastes and the elimination of toxic components during the production process. Reduction of environmental burden through the complete product life cycle must be considered in SD, in addition to the well-established concerns about safety and health. Environmental impacts must also be considered in the design, delivery and disposal of each product. Therefore, the main purpose of SD must be to integrate efforts in designing clean processes, products and services in order to achieve a global result that is more effective in preventing environmental damage than isolated solutions. The design stage is the adequate moment to approach environmental impact minimization [6].

Eco-Design is an adequate strategy for approaching the problem, since the entire life cycle of the product or service system must be discussed [4, 10, 24]. If the economic, social and legal aspects are also considered then the sustainability of the productive system can be completely evaluated, because of the interconnected views [6]. For example, the reduction of raw material usage may reduce both the environmental burden and the cost of the product; thus, sustainability and economy aspects are related. Legal aspects are also relevant in a global economy, since many countries have restrictions on import products whose production process does not follow certain conditions and, in the future, perhaps, compliance with SD will be mandatory. Actually, there is already a market share for "green products", so this concern may not be disregarded.

Ecological product design must consider [6]: 1) Optimal function and ecology efficiency; 2) Durability; 3) Minimization of the energy and non-renewable resources use during the product life cycle; 4) Minimization of the use of non-biodegradable substances; and 5) Recycling and waste management.

\subsection{PSS - Product Service System}

PSS integrates products and services in order to design a system able to meet the clients' demands. The main idea is to sell client satisfaction instead of selling products only [29]. This stems from a new concept of mutually dependent products and services focusing on the compliance of a client demand instead of the physical result of an industrial production process [28].

PSS potentialities include the synergy among the environmental benefits and other product issues such as profit and competitiveness [13, 29, 30]. However, PSS may not result in a sustainable solution because of the rebound effects. They are the result of changes in consumer behaviour or profile due to the introduction of a new PSS, even when it is designed to reduce the environmental burden. The classical example is related with the use of computers and Internet for text editing and exchanging. It could avoid the waste of paper but, at least in the beginning, computers and the Internet only increased our capacity to produce content and a large deal of this content was printed, causing an overall waste of paper many times greater than previously thought [29].

A PSS may be sustainable or not and the following aspects must be analyzed along the life cycle of products and services in PSS [29]: 1) Greenhouse effect analysis to evaluate gas emissions; 2) Use of renewable resources, e.g. raw materials; and 3) Overall environmental and social impacts. A sustainable PSS designer may require 
ability to undertake the business, understanding the social context and applying patterns from a different point of view. The result may be a new product, a new service, or a new system including both a new product and a new service, so as to satisfy the client demands.

Sustainability may rely on providing added value to the entire PSS life cycle by establishing infrastructure to enable its implementation and rules for ownership and usage, resulting in benefits to the consumer. It means, for instance, that a client may operate the product with decision power for a while but, when the contract is over or the product or system is no longer useful, the producer may take it back, deciding new sales opportunities or disposal treatment. This simplifies the control of the PSS life cycle and allows the establishment of more effective rules for reducing the environmental burden.

\subsection{LCA - Life Cycle Assessment}

Life Cycle Assessment is defined by ISO [20, 21]. [20] establishes the main principles and the framework for the adoption of LCA in a language accessible to a broad target audience, and [21] presents the formal requirements for a more specialized audience, and is hence the core reference document for LCA practitioners [11]. [20] and [21] are currently the only valid references for LCA, replacing the older versions.

LCA is defined as the "compilation and evaluation of the inputs, outputs and potential environmental impacts of a product throughout its life cycle" [20] and it includes [18]: 1) Analysis of the problem origins for each product; 2) Comparisons among the variations of the same product; 3) Adequate design of new products; and 4) Product choice, considering a variety of analogous offers. In LCA, the term product includes goods and services at the operational and strategic levels, and all types of impacts of a product on the environment must be considered [18].

LCA must be as quantitative as possible, so as to allow comparisons among different products that accomplish the same function. For comparative analysis, the function provided by the acquisition or rental of a product must be considered, as well as both the present and future environmental burdens.

The guiding principles of LCA are transparency, credibility, comprehensiveness and consistency [11]. Transparency interferes with the LCA planning and execution, and establishes that the scientific approach or international conventions must be the base for decisions [20]. For credibility, a comparative assertion considering unambiguousness, clarity and accuracy, and the intention to disclose it to the public, is fundamental. Comprehensiveness refers to the consideration of all aspects of the environment, resources and human health, using a cross-media perspective so as to identify potential trade-offs. Consistency refers to the harmony among all parts of the process.

LCA must consider the entire life cycle of the productive process $[20,21]$, including: 1) Material choice - extraction and acquisition of the raw material; 2) Manufacturing - energy required for the production and distribution processes; 3 ) Product use - consumption aspects; and 4) Product disposal - treatment and final disposal of the product at the end of its life cycle.

The broad scope of the analysis usually results in the simplification of some aspects of a product, so LCA has limitations [18]. For instance, LCA does not address 
local impacts and dynamic approaches, and does not consider the rebound effects from the introduction of a new product onto the market, since the analysis is linear. Data availability for the analysis may also represent an important constraint in some cases. Social and economic impacts are outside the scope of LCA. There are intrinsic limitations when conclusions and recommendations about a product are being prepared, so the consistency of the technique is dependent on the methodological approach [20]. A critical review or third party reports are strongly recommended [11].

LCA allows environmental management and environmental performance evaluation, identifies relevant aspects of products within a specific context, incorporates environmental concerns into product design and development, and quantifies and certifies greenhouse gas emissions.

However, LCA may be dependent on the size, culture, product, internal system and strategy of each organization. Hence, in the SD context, LCA adoption is even more complex, requiring many techniques and software packages.

\subsection{Sustainable Design}

$\mathrm{SD}$ is "a strategic activity to conceive and develop sustainable solutions" [27]. The solution must allow people to live with quality of life but consuming less environmental resources. SD must consider social and economic impacts $[25,26]$.

Social impacts involve [26]: 1) Evaluation of the best alternative between a product or a service for meeting a specific demand; 2) Verification of social aspects related to the raw material, e.g.: extraction and processing, ownership rights and trading arrangements; 3) Employment conditions; 4) Impacts and investments on the local community; and 5) Adverse impacts for local and global communities, considering safety and health aspects.

It is necessary to consider the surrounding world and the recommended economic model is the distributed one; power generation, creative communities and cooperative networks take place [33]. The consumption of natural resources and innovation would be based on local structures, enterprises, initiatives and communities. The main question is how to practice SD in a global economy.

The economic impact includes evaluating the cost-effectiveness of a product or service compared to other available solutions. A balance between ecological and economic issues is necessary, in addition to technological development, specific legislation and changes in social life [9]. Life cycle must be considered to evaluate the nature and quality of PSS, confronting economic and environmental aspects to obtain significant environmental improvements [9]. Social and economic issues depend on the product or service that is being developed, but both aspects must be considered in all steps of SD.

Relevant aspects of SD are [5]: 1) Sustainable consumption is as important as sustainable production so as to avoid the rebound effects; 2) Replacing a product with a service will not necessarily improve its sustainability; 3) Consumer satisfaction is divided into one-off occurrences (e.g.: eating a hamburger) or continuous occurrences (driving a car); 4) Products and services have a different apprehension for the consumers; 5) The time to consumer satisfaction is different from a product or service use, so the consumer must thoroughly understand the substitution of one product for a service. 
SD of products and services also must consider functionality, quality, demand, customer requirements, technical feasibility and compliance with legislation and technical specifications, as well as any other standards [26].

\section{A Reference Process for Sustainable Design}

The reference process considers products, services and other dimensions of the problem, in order to balance economic and social aspects with the environmental approaches provided by PSS and LCA.

The aim is to provide a balance among environmental protection, social equity and economic prosperity, maintaining the traditional product design requirements, such as quality, demand, technical and cost issues [26]. LCA requires the analysis of the product life cycle $[20,21]$, which will be made in this paper considering the standard viewpoint.

The reference process for SD will extend the concepts of ecodesign, design for disassembly, design for recycling [12], LCA, PSS and social and economic impacts. All concepts are integrated in a single process, considering the basic product life cycle, Fig. 1, according to the standard [11].

The reference process presented in Fig. 2 was defined in order to incorporate all relevant aspects of SD. The steps describe the activities to be performed during the design stage of a product. Some steps or activities must require software tools or experts to evaluate the environmental impacts.

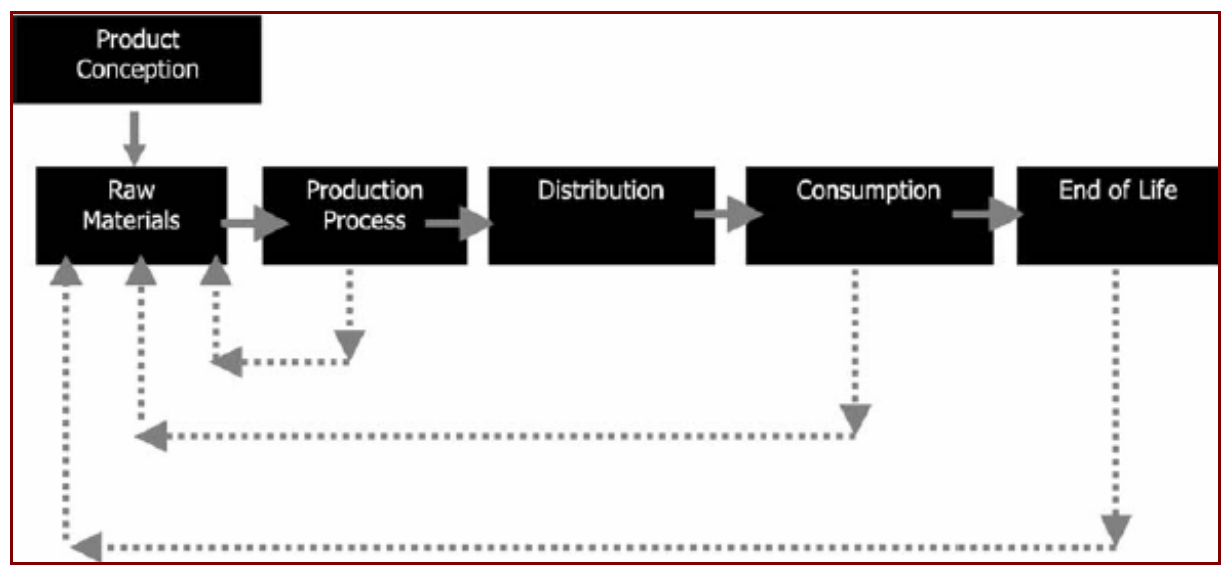

Fig. 1. The basic product life cycle can be summarized as the application of six main steps, from the raw material choice to the product disposal [8]

The six steps of the Reference Process for SD are described in Fig. 2. They are:

Step 1 - Functionality conception: this step defines the functionalities of the item to be designed, analyzes its environmental impacts and the alternatives between products and services.

Step 2 - Raw material acquisition: this step must consider minimizing the 
volume of material used, especially non-renewables, and replacing the type of raw materials so as to reduce environmental impact; besides this, it must analyze the trade-offs between extracting and processing the raw materials and the transport conditions.

Step 3 - Manufacturing: the purpose of this step is to optimize the technology for manufacturing a product or delivering a service, by eliminating or reducing emissions to the air, effluents, waste, and energy use.

Step 4 - Trade and delivery: this step defines the requirements for the transport related to the delivery of a product or service, including its volume and nature, and the type of vehicle and fuel to be used; the purpose is eliminating or minimizing emissions to the air, effluents, waste, and energy use.

Step 5 - Use and maintenance: the purpose of this step is eliminating or reducing the waste related to a product or service, including its packaging and consumption.

Step 6 - Reuse, recycling, energy recovery and disposal: the purpose of this step is to extend the life of a product or to facilitate the recovery of its components for reuse, recycling, and treatment/disposal. The design must be modular, so as to maximize the upgradability, or adequate to allow the repair of eventual damages to the product.

The economic aspects are the same for all steps of the process, and the purpose is to verify the cost-effectiveness of products or services in all the previous steps of the process, comparing them to available products, evaluating environmental and nonenvironmental costs, and analyzing global vs. distributed economy.

Before starting the design stage, data about the raw material, the manufacturing process and the trade and delivery processes are essential. Data availability is a serious limiting factor for SD.

\section{A Case Study: The Ethanol Program in Brazil}

This section presents a brief overview of the ethanol program in Brazil so as to illustrate the reference process for SD. The purpose is only to comment on each step of the reference process using ethanol as an example. The evaluation of this program, the analysis of the possibilities for its adoption worldwide, and all types of metrics are outside the scope of this section so as to simplify the example and keep the focus on the reference process. The ethanol program in Brazil will be presented according to the steps of the process, even if this process was not available when the product was conceived.

Step 1 - Functionality conception: Brazil was critically affected by the oil crisis of 1973 and, in addition to the increased efforts in prospecting petroleum under the deep waters of the continental shelf, the country started the PROALCOHOL program so as to produce large amounts of sugarcane ethanol [15]. Sugarcane ethanol is a substitute for gasoline. It has the same purpose as gasoline, similar properties, the same health and safety requirements are necessary and the social and economic impacts are related, since the purpose is to reduce the price of the fuel, and the legal aspects are abided by [15]. 


\begin{tabular}{|c|c|c|c|c|c|c|}
\hline 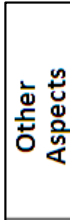 & 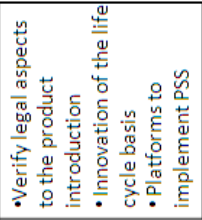 & \multicolumn{2}{|c|}{ 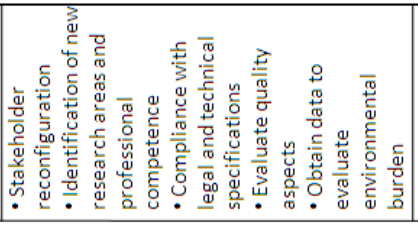 } & 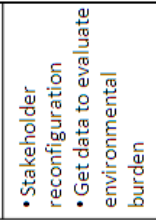 & 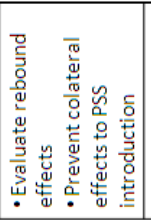 & 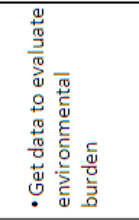 \\
\hline 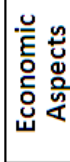 & \multicolumn{6}{|c|}{ 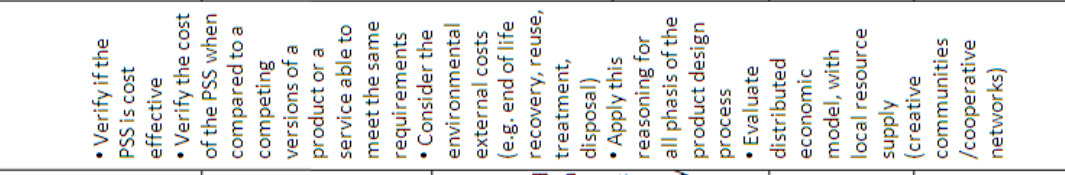 } \\
\hline 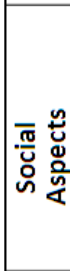 & 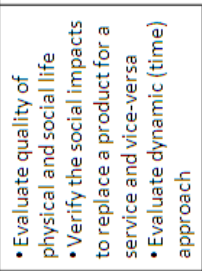 & 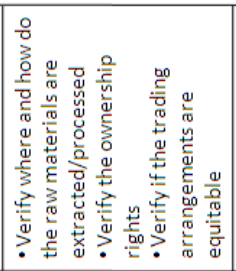 & 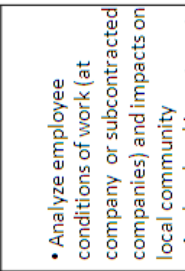 & 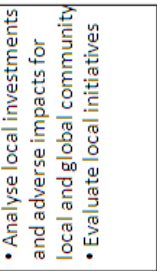 & 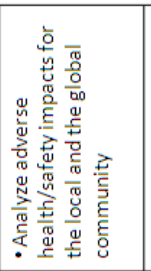 & 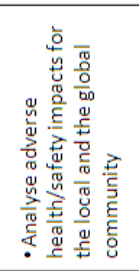 \\
\hline 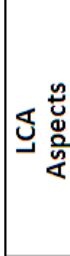 & 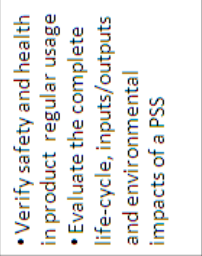 & 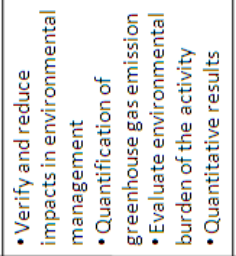 & 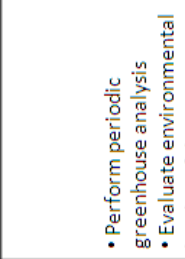 & & 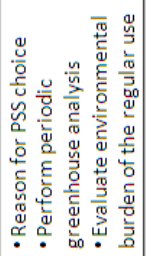 & 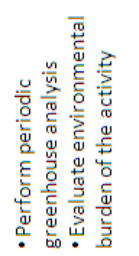 \\
\hline 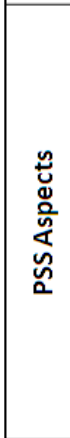 & 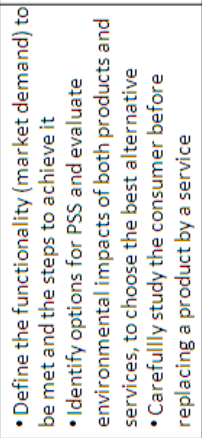 & 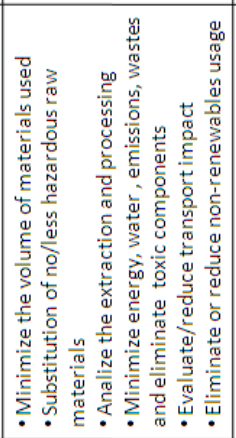 & 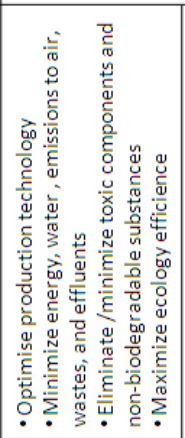 & 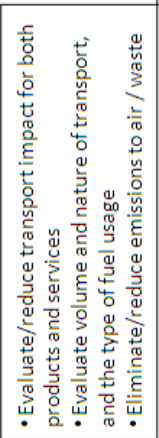 & 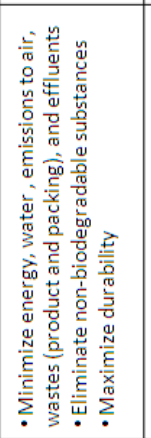 & 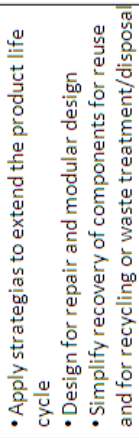 \\
\hline 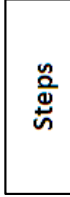 & 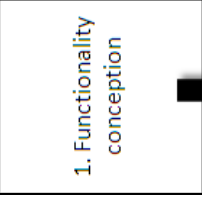 & 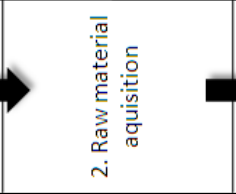 & . & & & 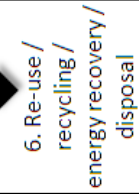 \\
\hline
\end{tabular}

Fig. 2. A Reference Process for Sustainable Design

Steps 2 and 3 - Raw material acquisition and Manufacturing: The raw material for ethanol, in Brazil, is sugarcane. Therefore, raw material acquisition is related to sugarcane production, and sugarcane production is related to ethanol production, both will hence be studied together in this example. 
Since the beginning of PROALCOHOL, the legislation has improved and the land use has been severely controlled, avoiding deforestation and preserving natural ecosystems $(60 \%$ of the sugarcane production is in the state of São Paulo, no sugarcane is produced in Amazonia as the humid climate is unsuitable for sugar production), the adoption of controlled fertirrigation practices is being applied, the harvest burning practices are being phased-out through a strict legal enforcement, and the industrial sugarcane and ethanol plants have their air emissions controlled [5]. From the economic point of view, new investments are private and the cost of the production of sugarcane is decreasing [5]. From the social point of view, at least 700,000 jobs were created with the sugarcane production for ethanol while the competition for land with food production has been shown to be a myth [5]. Energy needs for its production come from the bagasse, which is used to generate power and, since the Brazilian Energy Matrix is mainly based on hydropower, the indirect consumption of fossil fuels is low [17]. The direct consumption of fossil fuels in these steps is related to the use of fertilizers and harvest machines and the main liquid effluents of ethanol are vinasse and wastewaters [17]. There are laws and technical standards to regulate vinasse disposal and techniques to reduce organic pollutants in wastewater [17].

Step 4 - Trade and delivery: One of the main requirements for trading ethanol is to prepare the vehicles for replacing gasoline with ethanol [17]. Since the beginning of the PROALCOHOL, the multinational automobile industries in Brazil agreed to produce automobiles with converted motors and have introduced all the necessary engine and vehicle modifications for ethanol use. Even gasoline vehicles use blends from $20 \%$ to $26 \%$ of ethanol. Nowadays, many cars in Brazil use a flexible fuel technology, which means the driver can choose between ethanol and gasoline or a mix of both.

Besides the vehicles, the availability of an infrastructure for ethanol pumps in service stations and ethanol distribution is required and this infrastructure started to be developed in Brazil at the beginning of the PROALCOHOL [17]. Transportation trucks, however, still use fossil fuels, but their emissions are included in the studies for evaluating the greenhouse gas emissions of ethanol [22].

Step 5 - Use and maintenance: Nowadays, ethanol is a renewable replacement for gasoline; its GHG emissions are reabsorbed by photosynthesis during the growth of sugarcane in the following season [17]. The only difference from the use of gasoline in Brazil is related to the consumption of fuel. From the economic point of view, it is regulated by the ethanol price, which is usually smaller than that of gasoline or at least in the same proportion. The consumption of ethanol in Brazil tends to drop when this proportion in not respected.

6) Reuse, recycling, energy recovery and disposal: Only the ethanol greenhouse gas emissions must be considered in this step. There is the reuse of bagasse for energy recovery and other aspects related to the ethanol production, but they were analyzed in the previous steps.

In this case, as compared to gasoline, ethanol has additional benefits, the importance of which was reinforced years after the beginning of the PROALCOHOL program. They are: a) The use of ethanol as fuel has smaller impact on the environment because it avoids $\mathrm{CO} 2$ emissions as compared to gasoline [17, 22]; and b) Ethanol has a favorable energy balance and is a renewable and sustainable energy source [16]. 


\section{Discussion}

The definition of this reference process shows that many aspects must be considered and weighted so as to put SD into practice.

However, the process is mainly a guideline and researchers and companies must define more specific criteria for each step of the reference process. The use of numeric criteria for evaluating products and services is mandatory in order to define comparable criteria on which to base design activity and the consumer rules.

Note that the reference process uses words such as "minimize" or "maximize", and these are not adequate or precise evaluations. However, more restricted criteria do not depend on process modeling but on the research in other areas of knowledge such as Chemistry and Physics that are able to define numerical values for LCA. Besides, as a reference process, this process must be customized for each company or production segment, by detailing each step and defining the metrics and parameters for its adoption as a regular company process.

Some activities identified in the reference process are very difficult to perform. For instance, stakeholder reconfiguration may involve the pressure of the investors or the interference of external partners, such as governments, to achieve good results. Another difficulty is to evaluate rebound effects. Some social impacts may also be hard to evaluate and, in this case, a consulting service may be a good strategy to adopt.

The definition of a reference process is a starting point in providing a more accurate evaluation of SD. It also represents the first step in the software engineering process for designing a SOA-based solution for the development of information systems for SD. The main challenge is building tools for data synthesis and analysis in SD, which must be able to get results faster and allow easy visualization, interpretation, and analysis of environmental information.

The purpose of the reference process is also to integrate the activities so as to obtain a global maximum result instead of only local results, directing the production towards client satisfaction and improvements in quality of life. This may produce unexpected synergies to improve many aspects of a consumer's satisfaction, including profit, competitiveness and environmental benefits.

\section{Conclusion}

The reference process to design information systems for SD based on LCA, PSS, social and economic aspects captures the main steps and activities involved in SD. The process stratifies the design activity and performs a careful analysis of each step so as to identify the problems and, within the context of a SOA-based solution, to capture the software requirements.

Since the designers must work with sustainability concepts, the reference process presents a list of activities to be performed and is also a guide to beginners. Considering the complexity of SD, the clear definition of each step for each company is mandatory. 
Acknowledgments. The authors thank FINEP - Financiadora de Estudos e Projetos (Research and Projects Financing) - from the Ministry of Science and Technology MCT/Brazil for supporting the PROSENSAP project (01.08.0566.00).

\section{References}

1. Bass, L., Clements, P., Kazman, R.: Software Architecture in Practice, 2nd edn. Addison Wesley, Boston (2005)

2. Bichler, M., Lin, K.J.: Service-Oriented Computing. Computer 39(3), 99-101 (2006)

3. Brundtland, G.: Our Common Future. Oxford University Press, Oxford (1987)

4. Charter, M., Young, A., Kielkiewics-young, A., Belmane, I.: Integrated Product Policy and Eco-Product Development. In: Charter, M., Tischner, U. (eds.) Sustainable Solutions. Developing Products and Services for the Future, pp. 98-116. Greenleaf Publishing, Sheffield (2001)

5. Coelho, S.T., Goldemberg, J., Lucon, O., Guardabassi, P.: Brazilian sugarcane ethanol: lessons learned. Energy for Sustainable Development, X-2 (June 2006)

6. Dewulf, W., Duflou, J.: Proc. of CIRP Seminar on Life Cycle Engineering, Copenhagen, Denmark (May 2003)

7. Ehrenfeld, J.R.: Industrial Ecology: Coming of Age. Environmental Science \& Technology 36(13), 280A-285A (2002)

8. Endrei, M., Ang, J., Arsanjani, A., Chua, S., Comte, P., Krogdahl, P., Luo, M., Newling, T.: Patterns - Service-Oriented Architecture and Web Services. IBM Redbook (2004), http: / /www.redbooks.ibm.com/redbooks/pdfs/sg246303.pdf

9. Feldmann, K.: Foreword. In: Feldmann, K. (ed.) Recy 1994, Presentations of the 2nd International. Seminar on Life Cycle Engineering, Erlangen, October 10-11. Meisenbach Verlag, Bamburg (1994)

10. Fiksel, J.: Design for Environment: Creating Eco-Efficient Products and Processes. McGraw-Hill, New York (1996)

11. Finkbeiner, M., Inaba, A., Tan, R.B.H., Christiansen, K., Klüppel, H.: The New International Standards for Life Cycle Assessment. International Journal on LCA 11, 80 85 (2006)

12. Gertsakis, J., Lewis, H., Ryan, C.: A guide to EcoReDesign. Centre for Design at RMIT. RMIT University, Melbourne (1997)

13. Goedkoop, M., van Halen, C., te Riele, H., Rommes, P.: Product services systems, ecological and economic basics, Report 1999/36. VROM, The Hague (1999)

14. Goldemberg, J.: The evolution of ethanol costs in Brazil. Energy Policy 24(12), 11271128 (1996)

15. Goldemberg, J.: The ethanol program in Brazil. Institute of physics publishing environmental research letters. Environ. Res. Lett. 1, 014008 (5pp) (2006), doi:10.1088/ 1748-9326/1/1/014008

16. Goldemberg, J.: Ethanol for a Sustainable Energy Future. Science 315, 808 (2007), doi:10.1126/science. 1137013

17. Goldemberg, J., Coelho, S.T., Guardabassi, P.: The sustainability of ethanol production from sugarcane. Energy Policy 36, 2086-2097 (2008)

18. Guinée, J.B., Gorée, M., Heijungs, R., Huppes, G., Kleijn, R., de Koning, A., van Oers, L., Wegener Sleeswijk, A., Suh, S., Udo de Haes, H.A., de Bruijn, H., van Duin, R., Huijbregts, M.A.J.: Handbook on Life Cycle Assessment: Operational Guide to the ISO Standards. Institute of Environmental Sciences-Universiteit Leiden. Eco-Efficiency in Industry and Science, vol. 7. Kluwer Academic Publishers, Dordrecht (2002) 
19. Huhns, M., Singh, M.P.: Service-Oriented Computing: Key Concepts and Principles. IEEE Internet Computing 9(1), 75-81 (2005)

20. ISO/IEC 14040. LCA - Principles and Frameworks (2006)

21. ISO/IEC 14044. LCA - Requirements and Guidelines (2006)

22. Macedo, I.C., Seabra, J.E.A., Silva, E.A.R.: Green house gases emissions in the production and use of ethanol from sugarcane in Brazil: The 2005/2006 averages and a prediction for 2020. Biomass and Bioenergy 32, 582-595 (2008)

23. Meadows, D., et al.: The Limits to Growth. Universe Books, New York (1972)

24. McAloone, T.: Industrial Application of Environmentally Conscious Design. Engineering Research Series 1, Professional Engineering. McGraw-Hill, London (2000)

25. McAloone, T.C., Andreasen, M.M.: Design for utility, sustainability and societal virtues. In: International Design Conference - Design, May 18-21 (2004)

26. Maxwell, D., van der Vorst, R.: Developing sustainable products and services. Journal of Cleaner Production 11, 883-895 (2003)

27. Manzini, E.: Design research for sustainable social innovation. In: Michel, R. (ed.) Design Research Now, pp. 233-245. Birkhäuser, Basel (2007)

28. Manzini, E., Vezzoli, C.: Product-service systems and sustainability. Opportunities for sustainable solutions. In: United Nations Environment Programme, Division of Technology Industry and Economics, Production and Consumption Branch. CIR.IS Politecnco di Milano, Milan (2002)

29. Manzini, E., Vezzoli, C.: A strategic design approach to develop product service systems: examples taken from the 'environmental friendly innovation' Italian prize. Journal of Cleaner Production 11, 851-857 (2003)

30. Mejcamp, R.: Changing consumer behavior through eco-efficient services. Delft University of Technology, Delf (2000)

31. Papazoglou, M.P., Traverso, P., Dustdar, S., Leymann, F.: Service-oriented computing: state of the art and research challenges. Computer 11, 38-45 (2007)

32. Santana, F.S., Siqueira, M.F., Saraiva, A.M., Correa, P.L.P.: A reference business process for ecological niche modelling. Ecological Informatics Journal 3(1), 75-86 (2008)

33. Vezzoli, C.: Design for sustainability: the new research frontiers. In: 7th Brazilian Conference on Design, P \& D, Curitiba, August 9-11 (2006) 